\title{
Association analysis between Lipoxygenase activity and SSR markers in wheat grains
}

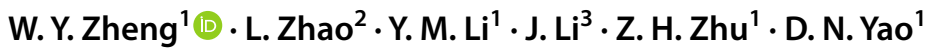

Received: 14 January 2021 / Accepted: 22 April 2021 / Published online: 22 May 2021

(c) The Author(s) 2021

\begin{abstract}
Lipoxygenase (LOX) activity is closely related to wheat processing and storage quality. In the present research, ten wheat cultivars were used to compare the effects of genotype, location, year, and their interactions on the LOX activity. Furthermore, 123 wheat cultivars were evaluated for LOX activity with 192 simple sequence repeat (SSR) markers and to identify elite alleles related to LOX activity. The results indicated that LOX activity was highly affected by genotype (variety) than that by the location. A total of 22 SSR molecular marker loci with a significant or very significant correlation with LOX activity were identified on performing association analysis. In 3 years, only one molecular marker locus associated with LOX activity was detected (WMC488); in 2 years, seven molecular marker loci were detected, while in only 1 year, the other 14 molecular marker loci were detected. A total of 7 and 6 marker loci significantly related to LOX activity accounting for $31.2 \%$ and $27.2 \%$, respectively, were located in homologous groups 4 and 5, and group 7 . This research provided the theoretical basis and the markers for molecular-assisted wheat breeding that facilitate the breeding process in the processing and storage quality of grains.
\end{abstract}

Keywords Wheat processing and storage quality $\cdot$ LOX $\cdot$ SSR makers $\cdot$ Association analysis

\section{Introduction}

Lipoxygenases (EC 1.13.11.12., LOX) are isoenzymes that contain non-heme iron and are widely found in many plants. They catalyze the oxygenation of polyunsaturated fatty acids with Cis, Cis-1, and 4-pentadiene structure to produce polyunsaturated hydroperoxides with conjugated double bonds (Guo et al. 2017; Boyington et al. 1993).

The main stored grain crop in China is wheat, and the good quality of stored grain is of great importance to food security. However, various factors affect the storage quality of wheat, including the climatic conditions during harvest season, air drying, transportation, storage, and other external environmental conditions and internal factors such as

W. Y. Zheng

zhengwenyin_75@163.com

1 School of Agronomy, Anhui Agricultural University, Hefei 230036, China

2 Institute of Crop Research, Anhui Academy of Agricultural Sciences, Hefei 230036, China

3 Biotechnology Center of Anhui, Agricultural University, Hefei 230036, China oxidase (Borrelli et al. 2008). Some studies have confirmed the effect of LOX activity on the storage quality of wheat. Trufanov et al. (2007) reported that low LOX activity was beneficial to the preservation of the nutritional components of flour and its products. It was also found that reducing LOX activity is an effective method for long-term conservation of germplasm resources, because low LOX activity can effectively reduce the oxidation reaction of seed lipids and extend the storage period (Leenhardt et al. 2006).

Studies have shown that the LOX gene family exists in plants (Feussner and Wasternack 2002). Recently, many researches have been conducted on LOX gene mapping, cloning, isolation, and identification of wheat using molecular marker technology. In the last century, the location of the LOX gene of common wheat was on chromosomes 4 and 5 (Zhou et al. 2019; Hessler et al. 2002). Somers et al. (2003, 2004) and Geng et al. (2011a) developed and indicated several SSR markers interlinked with LOX active QTL on chromosomes 4B and 1A, respectively. Pshenichnikova et al. (2008) believed that an AFLP molecular marker Xbcd1262, located in 4BS, was closely linked to LOX activity. Two complementary dominant markers LOX16 and LOX18 were used on the developed $4 \mathrm{~B}$ to detect the LOX activity 
(Geng et al. 2011a, b, c; Zhang et al. 2016). Meanwhile, great progress has been made in the study of the locus of the LOX gene family function. Lpx-B1 locus and variation types on the durum wheat 4BS chromosome were identified and believed that different variation types at different loci had significant effects on the LOX activity (Hessler et al. 2002). Lpx-3, Lpx-B1.1, and Lpx-B1.2 genes in durum wheat were homogeneously cloned (Carrera et al. 2007) and found the large fragment deletion of Lpx-B1.2 gene could significantly reduce the LOX activity. Furthermore, a new gene Lpx-B1.3, which is a pair of alleles to Lpx-B1.2 at the locus of Lpx-B1, was detected (Verlotta et al. 2010). More and more studies demonstrated that a multigene network and also major genes regulate the LOX activity in wheat grains (Feng et al. 2010; Geng et al. 2011j; Feng et al. 2012) and the phenotypic differences may be due to the presence of different alleles in different germplasm resources (Gupta et al. 2005). Therefore, it is necessary to determine elite allelic genes associated with the LOX activity in wheat grains.

Considering the importance of association mapping for dissecting the complex quantitative traits of wheat, SSR markers were used to analyze the population structure of 123 wheat materials based on the genotype and environment analysis and the interaction between genotypes and the environment. Furthermore, SSR markers associated with LOX activity in wheat were discussed through correlation analysis between SSR markers and target traits, so as to provide a reference for related molecular-assisted selection.

\section{Materials and methods}

\section{Plant materials}

Materials used in multiyear and multipoint experiments include Zhongyou 9507, E-en 4, Lumai 22, Wan Mai 48, Neixiang 188, Yannong 19, Haoyou 9409, Zhou Mai 16, Yang Mai 15, Huaiyin 9467. They were planted in four test sites in Hefei, Luan, Fengtai, and Lingbi, Anhui Province, over 2 years. In this experiment, block groups were designed randomly with three repetitions. Planting, field management, and harvest were performed according to local cultivation requirements. A total of 123 wheat germplasm resources were used for correlation analysis, which were sown in Research Farm of Anhui Agricultural University, Hefei, $31^{\circ} 52^{\prime} \mathrm{N}, 117^{\circ} 17^{\prime} \mathrm{E}$, during the winter season of the years of 2013-2014, 2015-2016, and 2016-2017. The location belongs to subtropical humid monsoon climate with an average annual temperature of $15.7{ }^{\circ} \mathrm{C}$ and an average annual precipitation of 940-1000 mm. However, during 2015-2016, the temperature at wheat grain filling stage was higher than that in previous years, and the grain water content was lower when wheat was harvested. A randomized block design was used, with two repetitions, $2 \mathrm{~m}$ in length, $25 \mathrm{~cm}$ in-row spacing, and 100 seeds per row. All the materials were harvested and shelled in the following June, and the seeds were stored in safe water for 3 months after harvest.

\section{Experiment method}

\section{Determination of LOX activity in wheat}

A spectrophotometer was used to determine the LOX activity of the harvested wheat test material. Wheat grains of each variety were randomly selected to grind using a Perten 3100 laboratory mill (Perten Instruments, Hägersten, Sweden) equipped with a $1.5-\mathrm{mm}$ metal mesh screen to obtain whole wheat flour with similar particle size.

Enzyme extracting solution: $2.5 \mathrm{ml}$ phosphate buffer $\left(0.1 \mathrm{~mol} \mathrm{~L}^{-1}, \mathrm{pH} 7.5\right)$ was added into $0.5 \mathrm{~g}$ of whole wheat flour. Then, this was stored at $4^{\circ} \mathrm{C}$ for $30 \mathrm{~min}$, and it was shaken every $5 \mathrm{~min}$ to dissolve the flour completely with the extracting solution. After that, the solution was centrifuged at $8000 \mathrm{r} / \mathrm{min}$ and $4{ }^{\circ} \mathrm{C}$ for $10 \mathrm{~min}$, the enzyme extracting solution was extracted as supernatant.

Substrate configuration: first, $0.5 \mathrm{ml}$ Tween was dissolved in $10 \mathrm{~mL}$ boric acid buffer $\left(0.05 \mathrm{~mol} \mathrm{~L}^{-1}, \mathrm{pH} 9.0\right)$. Second, $0.5 \mathrm{ml}$ linoleic acid was added dropwise into the mixture, and the emulsion was formed. About $1.3 \mathrm{~mL}$ of $1 \mathrm{~mol}$ $\mathrm{L}^{-1} \mathrm{NaOH}$ solution was added until the solution was clear. Finally, $90 \mathrm{ml}$ boric acid buffer $\left(0.05 \mathrm{~mol} \mathrm{~L}^{-1}, \mathrm{pH} 9.0\right)$ was added, and $\mathrm{HCl}$ was used to adjust the $\mathrm{pH}$ to 7.0 , and then the volume was determined to $200 \mathrm{ml}$.

Reaction system: $0.3 \mathrm{~mL}$ linoleate substrate and $60 \mathrm{~L}$ enzyme extract were added to $2.5 \mathrm{~mL}$ sodium acetate buffer (0.05 mol L $\left.{ }^{-1}, \mathrm{pH} 5.6\right)$.

Enzymatic determination: the absorbance of reaction solution $\triangle \mathrm{A}$ was determined at $234 \mathrm{~nm}(\triangle \mathrm{A}$ is the change of light absorption value within the $30 \mathrm{~s}$, and the active unit was expressed as $\mathrm{AU} /(\min \mathrm{g})$ ).

LOX calculation formula is as follow:

$A=[\mathrm{OD}(30 \mathrm{~S})-\mathrm{OD}(15 \mathrm{~S})] / 0.01$,

where $A$ is the unit of enzyme activity, OD (30S) is the OD value of reaction $30 \mathrm{~S}$, OD (15S) is the OD value of reaction $15 \mathrm{~S}$, and 0.01 is a unit constant of enzyme activity.

\section{Extraction of genomic DNA from wheat}

SDS-TRis saturated phenol method (Ahmed et al. 2009) was used to extract genomic DNA from the young leaves harvested in 2017, and the DNA concentration and purity were detected and stored in a refrigerator at $-20{ }^{\circ} \mathrm{C}$ for use. 


\section{Screening of SSR primers}

A total of 275 SSR primers for the whole wheat genome were obtained from Graingenes (http://wheat.pw.usda. gov/GG2/index.shtm/) website. Then, 10 wheat materials with the far relative relationship were selected to screen the synthesized primers. Molecular data were determined using 1192 pairs of primers with good polymorphism and clear bands.

\section{PCR amplification}

About $10 \mathrm{uL}$ buffer including 1.0uL dNTPs with concentration of $2.5 \mathrm{mmol} \mathrm{L}^{-1}, 0.8 \mathrm{ul} 10 \times$ buffer (including $2.0 \mathrm{mmol} \mathrm{L}{ }^{-1} \mathrm{Mg}^{2+}$ ), $0.4 \mathrm{uL}$ upper primers and $0.4 \mathrm{uL}$ lower primers with concentration of $10 \mathrm{mmol} \mathrm{L}^{-1}, 0.10 \mathrm{uL}$ $5 \mathrm{UuL}^{-1}$ TaqDNA polymerase $0.10,2.0 \mathrm{uL}$ template with concentration of $50 \sim 60 \mathrm{ng} \mathrm{uL}^{-1}$, and 5.3UL double distilled water was used for PCR amplification method.

\section{Data analysis}

Variation analysis of LOX activity in wheat grains: The mean value, standard deviation, and variation coefficient were determined using EXCEL software. Statistical Package for the Social Sciences (SPSS) was used to evaluate the variance analysis and correlation analysis.

Analysis of elite allelic variation locus of LOX in wheat: To analyze the interpopulation genetic structure and determine the population structure and subsequent analysis strategies, 84 pairs of independent markers uniformly distributed throughout the whole genome of wheat without linkage were selected from 192 pairs of polymorphic SSR primers. The structure of the test group was determined using the STRUCTURE2.3.4 Software hybrid model. $K$ value is taken as $2-10$, and each $K$ value is run separately for 6 times. According to the $K$ value obtained from software analysis, the Bayesian method is used to estimate the number of subgroups of natural population materials.

The general linear model (GLM) and mixed linear model (MLM) of TASSEL software were used to analyze association analysis between primer markers and phenotypic traits. Significant $(P<0.05)$ marker loci associated with the two models were selected, and the interpretation rate of these marker loci to phenotypic variation was calculated.

\section{Results}

\section{Effects of genotype, location, year, and their interactions on the LOX activity}

The results obtained on performing variance analysis of two-year and four-point experiment (Table 1) show that the LOX activity of 10 wheat varieties, reached a significant difference in years. The effect of variety $\times$ year and location $\times$ variety $\times$ year reached an extremely significant level, while the difference of LOX activity between location and the interaction effect of location $\times$ year did not reach a significant level. As shown in Table 1, the percentage the sum of squares of variety in the total sum of squares is highest, up to 26.1, suggested genotype differences between breeds greatly affect LOX activity. While the location has the least effect, and the effect of the interaction of location, variety, and the year is more important than that of variety and year. As a result, it indicated that the difference of varieties (genotypes) had the greatest effect on the LOX activity of wheat, which is consistent with the study results of Borrelli et al. (2003).

\section{Phenotypic analysis of LOX activity in natural populations of wheat}

Statistical parameters of LOX activity of 123 wheat varieties in 3 years is shown in Table 2 . The maximum, minimum, and average values of LOX activity of the tested wheat varieties in 3 years are different, especially 2016 was lower than the other two year due to the low moisture content of harvested grains. While the variation coefficients are higher than $20 \%$. This suggests that the LOX

Table 1 Variance analysis of genotype, environment, and their interactions on wheat Lipoxygenase activity

\begin{tabular}{lrrrrr}
\hline Source of variation & SS & $d f$ & MS & $F$ & Percentage $^{\mathrm{a}}$ \\
\hline Set & 0.93 & 16 & 0.06 & & \\
Year & 25.49 & 1 & 25.50 & $71.21^{* *}$ & 10.54 \\
Location & 6.67 & 3 & 2.23 & 3.35 & 2.7 \\
Variety & 63.10 & 9 & 7.01 & $1.99^{*}$ & 26.1 \\
Location $\times$ Year & 1.99 & 3 & 0.66 & 1.86 & 0.8 \\
Variety $\times$ Year & 31.71 & 9 & 3.52 & $9.84^{* *}$ & 13.11 \\
Location $\times$ Vari- & 50.58 & 27 & 1.87 & $5.23^{* *}$ & 20.92 \\
$\quad$ ety $\times$ Year & & & & & \\
Error & 61.22 & 171 & 0.35 & & \\
Total & 241.72 & 239 & & & \\
\hline & "**"Refer to the significance of variance analysis at the 0.01 level \\
a Refers to the percentage of the sum of squares of every variation in \\
the total sum of squares
\end{tabular}


Table 2 Distribution of LOX activity in wheat cultivars in different years

\begin{tabular}{|c|c|c|c|c|c|}
\hline Year & Maximum & Minimum & $\begin{array}{l}\text { Average } \\
\text { value }\end{array}$ & $\begin{array}{l}\text { Standard } \\
\text { deviation }\end{array}$ & $\begin{array}{l}\text { Variable } \\
\text { coeffi- } \\
\text { cient }\end{array}$ \\
\hline $\begin{array}{l}2014 \mathrm{LOX} \\
\mathrm{AU} /(\mathrm{min} \\
\mathrm{g})\end{array}$ & 24.55 & 5.75 & 13.59 & 3.94 & 28.95 \\
\hline $\begin{array}{l}2016 \mathrm{LOX} \\
\mathrm{AU} /(\mathrm{min} \\
\mathrm{g})\end{array}$ & 13.40 & 2.25 & 7.86 & 2.00 & 25.43 \\
\hline $\begin{array}{l}\text { 2017LOX } \\
\mathrm{AU} /(\mathrm{min} \\
\mathrm{g})\end{array}$ & 18.75 & 5.40 & 11.12 & 2.47 & 20.35 \\
\hline
\end{tabular}

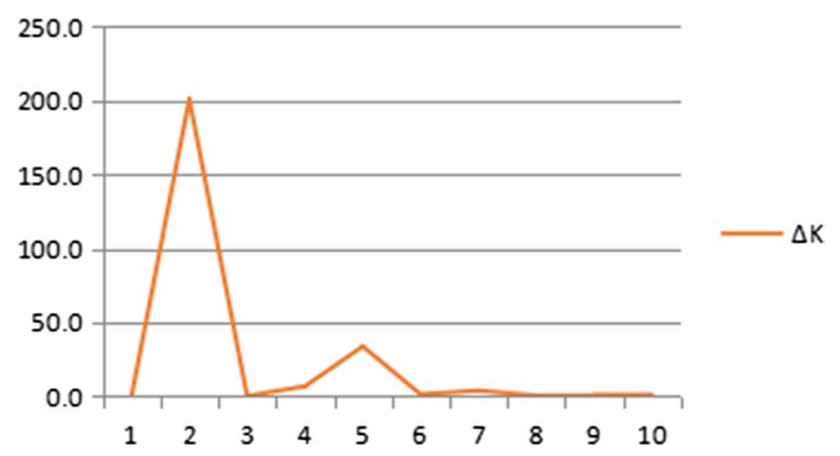

Fig. 1 True $\mathrm{K}$ of four groups $(K=2)$ generated by STRUCTURE

activity of the tested wheat materials showed a significant difference, and wide variation range, with a great potential for genetic improvement.

\section{Population structure analysis}

To evaluate the natural population structure, 83 pairs of independent SSR molecular markers uniformly distributed throughout the whole genome of wheat were selected from 192 pairs of SSR primers. The population structure of 123 wheat materials was determined using Structure 2.3.4's hybrid model. $K$ values were selected from 1 to 10 , and each $K$ value was run separately for 6 times. As per the obtained $K$ value, the number of subgroups of 123 wheat materials was estimated using the Bayesian method. When $K=2$, the maximum inflection point appears in the line graph, indicating that the group can be divided into two subgroups (Fig. 1). In addition, when $K=2$, Structure2.3.4 software plots the cluster graph using the $Q$ value (Fig. 2). Different colors represent different subgroups of the natural population of wheat (Fig. 2). The horizontal axis represents 123 wheat natural population materials, and the vertical axis represents the probability that the wheat material is distributed to two subgroups.

\section{Association analysis}

Significant marker loci $(P<0.05)$ associated with both models were selected, and the interpretation rate of these marker loci to the phenotype was calculated. With the $\mathrm{K}$ value of kinship obtained from Structure 2.3.4 analysis as the covariable, the GLM and MLM using TASSEL2.1 software were used to conduct SSR primer marker-trait associations (MTAs) on the natural population of 123 wheat materials. About 22 marker loci associated with LOX activity $(P<0.05)$ were detected, and results are shown in Table 3. Among them, there were 12 molecular marker loci associated with 2014, located at 1BL (BARC240 and BARC302), 3BS (WMC78), 4AL (BARC327), 4BL (BARC109), 5AL (BARC117 and BARC232), 6B(BARC136), 6BL(GWM219), 7AL(WMC488), and 7BL(WMC517), respectively. About $3.77 \sim 7.93 \%$ of phenotype was contributed by each marker locus, of which BARC117 on chromosome $5 \mathrm{AL}$ contributed $7.93 \%$ to the phenotype. Only three molecular marker loci were associated with 2016, located at 3BS (BARC139), 7AL(WMC488), and 7BL(BARC267). The contribution of each marker locus to phenotype was $4.82 \sim 6.50 \%$. There were 16 molecular marker loci associated with 2017, located at 1BL(BARC240 and BARC302), 2AL(GWM312), 2DS(BARC168), 4AL(BARC327), 4BL(BARC109), 4D(XMAG2944), 5AL(BARC117 and BARC232), 5BL(BARC156), 5DL(BARC320), 6B(BARC136), 7A(BARC281), 7AL(BARC108) and WMC488) and 7DS(GWM111). GWM312 made a large contribution of $12.13 \%$ to phenotypes.

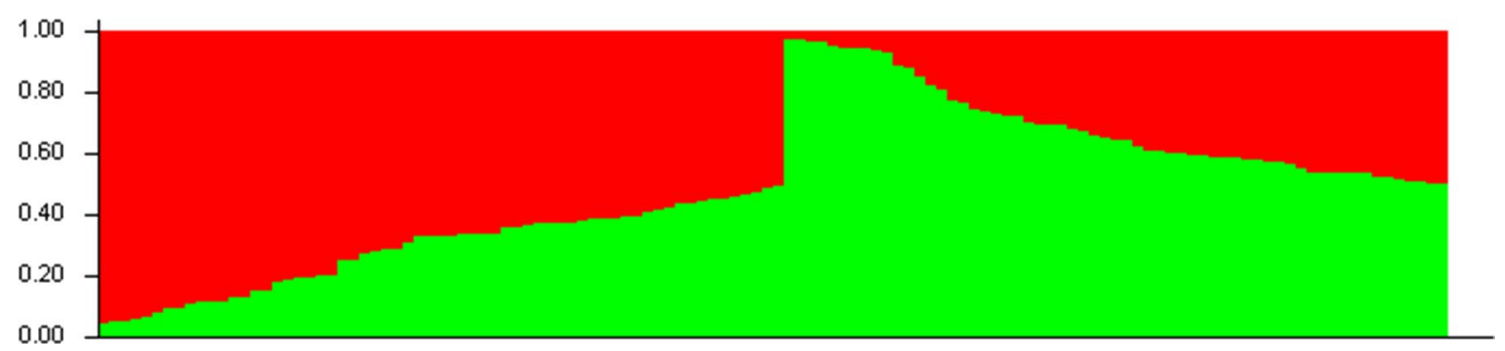

Fig. 2 Two populations inferred by STRUCYURE analysis 
Table 3 Marker loci associated with LOX activity detected in mixed linear models $(P<0.05)$ and their contribution to phenotypes

\begin{tabular}{|c|c|c|c|c|c|c|c|}
\hline \multirow[t]{2}{*}{ Marker } & \multirow[t]{2}{*}{ Chromosome } & \multicolumn{2}{|l|}{2014} & \multicolumn{2}{|l|}{2016} & \multicolumn{2}{|l|}{2017} \\
\hline & & $\bar{P}$ & $R^{2}(\%)$ & $\bar{P}$ & $R^{2}(\%)$ & $\bar{P}$ & $R^{2}(\%)$ \\
\hline BARC240 & $1 \mathrm{BL}$ & 0.0039 & 6.62 & - & - & 0.0226 & 4.14 \\
\hline BARC302 & $1 \mathrm{BL}$ & 0.0118 & 5.09 & - & - & 0.006 & 9.12 \\
\hline GWM312 & $2 \mathrm{AL}$ & - & - & - & - & 0.0003 & 12.13 \\
\hline BARC168 & 2DS & - & - & - & - & 0.0036 & 6.67 \\
\hline BARC139 & 3BS & - & - & 0.0139 & 4.82 & - & - \\
\hline WMC78 & $3 B S$ & 0.0059 & 6.06 & & & - & - \\
\hline GWM645 & $3 \mathrm{DL}$ & 0.0164 & 4.63 & - & - & - & - \\
\hline BARC 327 & $4 \mathrm{AL}$ & 0.0020 & 7.54 & - & - & 0.0122 & 4.98 \\
\hline BARC109 & $4 \mathrm{BL}$ & 0.0215 & 4.26 & - & - & 0.0276 & 3.87 \\
\hline XMAG2944 & $4 \mathrm{D}$ & - & - & - & - & 0.0013 & 8.07 \\
\hline BARC117 & $5 \mathrm{AL}$ & 0.0015 & 7.93 & - & - & 0.0239 & 4.06 \\
\hline BARC232 & $5 \mathrm{AL}$ & 0.0293 & 3.84 & - & - & 0.0234 & 4.09 \\
\hline BARC156 & $5 \mathrm{BL}$ & - & - & - & - & 0.0173 & 6.4 \\
\hline BARC320 & $5 \mathrm{DL}$ & - & - & - & - & 0.0480 & 3.13 \\
\hline BARC136 & $6 \mathrm{~B}$ & 0.0307 & 3.78 & - & - & 0.0330 & 3.63 \\
\hline GWM219 & $6 \mathrm{BL}$ & 0.0146 & 6.76 & - & - & - & - \\
\hline BARC281 & $7 \mathrm{~A}$ & - & - & - & - & 0.0059 & 5.98 \\
\hline BARC108 & $7 \mathrm{AL}$ & - & - & - & - & 0.0286 & 3.82 \\
\hline WMC488 & 7AL & 0.0307 & 3.77 & 0.0041 & 6.50 & 0.0038 & 6.58 \\
\hline WMC517 & $7 \mathrm{BL}$ & 0.0105 & 5.26 & - & - & - & - \\
\hline BARC267 & $7 \mathrm{BL}$ & - & - & 0.0312 & 5.53 & - & - \\
\hline GWM111 & 7DS & - & - & - & - & 0.0385 & 5.18 \\
\hline
\end{tabular}

Only one molecular marker locus, WMC488, was detected to be correlated with LOX activity in 3 years. In the 2 years, 7 molecular marker loci, namely BARC240, BARC302, BARC327, BARC109, BARC117, BARC232, and BARC136, were detected. The other 14 molecular marker loci were detected in only 1 year. Although a stable QTL for LOX activity in wheat grains was observed, the interaction between genotype and environment also significantly affects the LOX activity; this result is consistent with the results of variance analysis presented in Table 1.

\section{Discussion}

A set of standard procedures are recognized for the correlation analysis method, according to which natural population materials or seed resources with the extensive genetic background are selected, and population structure analysis is conducted. The most basic step of association analysis is to investigate phenotypic traits so that whether phenotypic traits are controlled by heredity can be determined and which environmental conditions and gene effects are stronger can be evaluated. The correlation analysis method cannot be used if the environmental effect is dominant. In results of this study demonstrates that genotype controls the LOX activity, which was determined by multiyear and multipoint experiments; this was consistent with previous studies (Borrelli et al 2008; Geng et al. 2011a, b, c). LOX activity in wheat grains was identified as a heritable trait that could be used for quality improvement.

LOX gene family exists in most plants(Barone et al. 1999; Liavonchanka and Feussner 2006; Carrera et al. 2007; Pshenichnikova et al. 2008). Allele variation at different loci had different effects on LOX activity of wheat (Geng et al. 2011a, b, c; Zhang et al. 2015). In this study, 22 SSR marker loci significantly correlated with LOX activity of wheat grains were obtained according to the GLM and the MLM of TASSEL software. A total of 7 significant marker loci accounting for $31.2 \%$, were observed in homologous groups 4 and. This result is consistent with previous studies (Hessler et al. 2002; Zhou et al. 2019). In the meanwhile, more marker loci related to LOX activity was observed on the homologous group 7. The 7A, 7B, and 7D chromosomes were associated with 3,2 , and 1 marker loci, respectively, therefore, gene loci for editing LOX in wheat grains is speculated to be on chromosome 7B. The other 8 markers were significantly different from the previous results of LOX gene localization. Therefore, further verification of the reliability of the markers should be carried out.

In this paper, 2-year and four points, experiments were conducted. The effect of genotype, environment, and interaction between genotype and environment on LOX 
activity was the genotype > interaction between genotype and environment $>$ environment. The results of correlation analysis show that the LOX activity of wheat varieties was consistent between different years, and the LOX activity of wheat was speculated to be largely controlled by genotypes. Association analysis also identified 22 SSR molecular marker loci with significant and extremely significant LOX activity. Among them, 12 marker loci were detected in 2014, and BARC117 on chromosome 5AL contributed to $7.93 \%$ of the phenotype. In 2016, only 3 molecular marker loci were identified to be associated and in 2017, 16 molecular marker loci were associated, and GWM 312 contributed to $12.13 \%$ of the phenotype (The molecular marker locus, WMC488, was associated with LOX activity, which was detected in 3 years. Seven molecular marker loci were detected in both two years, while the other 14 molecular marker loci were detected in only 1 year. A total of 7 significant marker loci accounting for $31.2 \%$, were observed in homologous groups 4 and 5 . Six marker loci related to LOX activity were observed in homologous group 7. Also, gene loci regulating the LOX activity in wheat grains might be present.

Authors' contributions WYZ, LZ, and YML developed the idea of the study, participated in its design and coordination and helped to draft the manuscript. JL, ZHZ, and DNY contributed to the acquisition and interpretation of data. XH provided critical review and substantially revised the manuscript. All authors read and approved the final manuscript.

Funding This study was supported by a grant from Anhui Provincial Natural Science Foundation (1608085MC70).

Availability of data and material The datasets used or analyzed during the current study are available from the corresponding author on reasonable request.

\section{Declaration}

Conflict of interest We declare that we do not have any commercial or associative interest that represents a conflict of interest in connection with the work submitted.

Open Access This article is licensed under a Creative Commons Attribution 4.0 International License, which permits use, sharing, adaptation, distribution and reproduction in any medium or format, as long as you give appropriate credit to the original author(s) and the source, provide a link to the Creative Commons licence, and indicate if changes were made. The images or other third party material in this article are included in the article's Creative Commons licence, unless indicated otherwise in a credit line to the material. If material is not included in the article's Creative Commons licence and your intended use is not permitted by statutory regulation or exceeds the permitted use, you will need to obtain permission directly from the copyright holder. To view a copy of this licence, visit http://creativecommons.org/licenses/by/4.0/.

\section{References}

Ahmed I, Islam M, Arshad W, Mannan A, Ahmad W, Mirza B (2009) High-quality plant DNA extraction for PCR: an easy approach. J Appl Genet 50(2):105-107

Barone R, Briante R, D'Auria S, Febbraio F, Vaccaro C, Del Giudice L, Borrelli GM, Di Fonzo N, Nucci R (1999) Purification and characterization of a lipoxygenase enzyme from durum wheat semolina. J Agric Food Chem 47(5):11924-11931

Borrelli GM, De Leonardis AM, Fares C, Platani C, Di Fonzo N (2003) Effects of modified processing conditions on oxidative properties of semolina dough and pasta. Cereal Chem 80(2):225-231

Borrelli GM, De Leonardis AM, Platani C, Troccoli A (2008) (2007). Contribution along durum wheat kernel of the components involved in semolina color. J Cereal Sci 76:1-9

Boyington JC, Gaffney BJ, Arnzel LM (1993) The three-dimensional structure of an arachidonic acid 15-lipoxygenase. Science 260:1482-1486

Carrera A, Echenique V, Zhang W, Helguera M, Manthey F, Schrager A, Picca A, Cervigni G, Dubcovsky J (2007) A deletion at the Lpx-B1 locus is associated with low lipoxygenase activity and improves pasta color in durum wheat. J Cereal Sci 45(10):67-77

Feng B, Dong ZY, Xu ZB, An XL, Qin HJ, Wu N, Wang DW, Wang $\mathrm{T}$ (2010) Molecular analyses of lipoxygenase (LOX) genes in common wheat and phylogenetic investigation of LOX proteins from model and crop plants. J Cereal Sci 52(3):387-394

Feng B, Dong ZY, Xu ZB, Wang DW, Wang T (2012) Molecular characterization of a novel type of lipoxygenase (LOX) gene from common wheat (Triticum aestivum L.). Mol Breed 30(1):113-124

Feussner I, Wasternack C (2002) The lipoxygenase pathway. Annu Rev Plant Biol 53:275-297. https://doi.org/10.1146/annurev.arplant. 53.100301 .135248

Geng HW, Zhang Y, He ZH, Zhang LP, Appels R, Qu YY, Xia XC (2011a) Molecular markers for tracking variation in lipoxygenase activity in wheat breeding. Mol Breed 28(1):117-126

Geng HW, Zhang Y, He ZH, Zhang LP, Appels R, Qu YY, Xia XC (2011ab) Molecular markers for tracking variation in lipoxygenase activity in wheat breeding. Mol Breed 28(1):117-126

Geng HW, Xia XC, Zhang LP, Qu YY, He ZH (2011bc) Development of functional makers for a lipoxygenase gene TaLOX-B1 on chromosome 4BS in common wheat. Crop Sci 52(2):568-576

Guo SL, Song ZZ, Ma RJ, Yang Y, Yu ML (2017) Genome-wide identification and expression analysis of the lipoxygenase gene family during peach fruit ripening under different postharvest treatments. Acta Physiol Plant 39:111

Gupta PK, Rustgi S, Kulwal PL (2005) Linkage disequilibrium and association studies in higher plants: present status and future prospects. Plant Mol Biol 57(4):461-485

Hessler TG, Thomosin MJ, Benscher D, Nachit MM, Sorrells ME (2002) Association of a lipoxygenase locu, Lpx-B1, with variation in lipoxygenase activity in durum seeds. Crop Sci 42:1695-1700

Leenhardt F, Lyan B, Rock E, Boussard A, Potus J, Chanliaud E, Remesy C (2006) Genetic variability of carotenoid concentration, and lipoxygenase and peroxidase activities among cultivated wheat species and btead wheat varieties. Eur J Agron 2006(25):170-176

Liavonchanka A, Feussner N (2006) Lipoxygenases: occurrence, functions and catalysis. J Plant Physiol 163(3):348-357

Pshenichnikova TA, Osipova SV, Permyakova MD, Mitrofanova TN, Trufanov VA, Lohwasser U, Roeder M, Boerner A (2008) Mapping of quantitative trait loci (QTL) associated with activity of disulfide reductase and lipoxygenase in grain of bread wheat. Russ J Genet 44(5):567-574 
Somers DJ, Fedak G, Savard M (2003) Molecular mapping of novel genes controlling Fusarium head blight resistance and deoxynivalenol accumulation in spring wheat. Genome 46(4):555-564

Somers DJ, Isaac P, Edwards K (2004) A high-density microsatellite consensus map for bread wheat (Triticum aestivum L.). Theor Appl Genet 109(6):1105-1114

Trufanov VA, Permyakova MD, Pshenichnikova TA, Ermakova MF, Davydov VA, Permyakov AV, Berezovskaya EV (2007) The effect of intercultivar substitution of wheat Triticum aestivum $\mathrm{L}$. chromosomes on lipoxygenase activity and its correlation with the technological properties of flour. Appl Biochem Microbiol 43:91-97

Verlotta A, De Simone V, Mastrangelo A, M., Cattivelli, L., Papa, R., \& Trono, D, (2010) Insight into durum wheat Lpx-B1: a small genefamily coding for the lipoxygenase responsible for carotenoid bleaching in mature grains. BMC Plant Biol 2010(10):263-273

Zhang FY, Chen F, Wu PP, Zhang N, Cui DQ (2015) Molecular characterization of lipoxygenase genes on the short arm of chromosome
4B in Chinese bread wheat (Triticum aestivum L.). Theor Appl Genet 128(8):14671479

Zhang Y, Wang X, Wang X, Jiang L, Liu F, He X, Liu S, Zhang X (2016) Development of multiplex-PCR systems for genes related to flour colour in Chinese autumn-sown wheat cultivars. Qual Assur Saf Crop Foods 8(2):231-241

Zhou GY, Zhang FF, Long WJ, Chen D, Wu XY, Cai Q, Wu SY (2019) Changes in viability of Lincang Hulled wheat grains under different storage temperatures and changes in lipoxygenase (LOX) Gene activity and expression levels during germination. Int J Agric Biol 21(5):979-988

Publisher's Note Springer Nature remains neutral with regard to jurisdictional claims in published maps and institutional affiliations. 